\title{
Paraphilias: definition, diagnosis and treatment
} Michelle A. McManus ${ }^{1 *}$, Paul Hargreaves ${ }^{1}$,Lee Rainbow ${ }^{2}$ and Laurence J. Alison ${ }^{3}$

Addresses: ${ }^{1}$ School of Forensic and Investigative Sciences, University of Central Lancashire, Preston, Lancashire, PR1 $2 \mathrm{HE}, \mathrm{UK}{ }^{2} \mathrm{Centre}$ for Invest-igative Psychology, ${ }^{3}$ Centre for Critical and Major Incident Psychology, Institute of Psychology, Health and Society, University of Liverpool, Eleanor Rathbone Building, Bedford Street South, Liverpool, Merseyside, L69 7ZA

*Corresponding author: Michelle A. McManus (mamcmanus@uclan.ac.uk)

FI000Prime Reports 2013, 5:36 (doi:10.12703/P5-36)

This is an open-access article distributed under the terms of the Creative Commons Attribution-Non Commercial License (http://creativecommons.org/licenses/by-nc/3.0/legalcode), which permits unrestricted use, distribution, and reproduction in any medium, provided the original work is properly cited. You may not use this work for commercial purposes.

The electronic version of this article is the complete one and can be found at: http://f 1000. com/prime/reports $/ \mathrm{m} / 5 / 36$

\begin{abstract}
There is a great deal of controversy concerning paraphilia, and defining what is normal versus deviant or disordered, given that this is to some degree dependent on cultural views of acceptability. In this article, we outline these issues and describe recent progress in diagnosing and treating paraphilias.
\end{abstract}

\section{Introduction}

There is a great deal of controversy concerning paraphilia, and defining what is normal versus deviant or disordered behavior. In part, this stems from the malleability of sexual norms across time and cultures, which creates problems for those defining and diagnosing paraphilia. Given that, in some circumstances, such diagnoses can be used to imprison and/or commit an individual based on their future likely danger to society, this adds another dimension to this problem. In this article we outline these issues and describe recent progress in diagnosing and treating paraphilias.

\section{What are paraphilias?}

Paraphilias are difficult to define, contentious as a basis for legal processes, and their classification not short of criticism. Stewart [1] suggests that paraphilia definitions are based on perceived deviations from inappropriate perfectionist ideals of sexual norms. Various 'preferences' and sexual interests have fallen in and out of being defined as paraphilic, for example, up until 1973 homosexuality was classified as paraphilic under the DSM (diagnostic and statistical manual of mental disorders)-II. Its subsequent removal led to some arguing that if homosexual orientation is not in itself abnormal, then the inclusion of other sexual behaviors classified as paraphilic cannot be justified as a concept and should be removed entirely from future editions [2]. Cantor [3] further outlined how even the interpretation of the word 'paraphilia' can dramatically alter what falls under its definition. This has implications for psychiatric diagnosis and treatment and impacts upon legal and political issues. Proposed additions 'for further study' for DSM-5 (hebephilia, paraphilic coercive disorder \& hypersexual disorder) attracted much prior criticism and were subsequently rejected by the Board of Trustees of the American Psychiatric Association (APA) [4]. Zonana [5] suggests a continuing trend of the DSM being more responsive to criminal justice concerns than mental illness. Undoubtedly, both time and culture play a role in defining the diverse range of paraphilic interests and bring with them criminal, legal and political contentions.

When exploring the term paraphilia, many would turn to the DSM-IV-TR (APA, 2000 [6]), and now the new DSM-5 (APA, 2013 [7]) for further information, even though all World Health Organization (WHO) member countries (including the United States) are required to follow the WHO International Classification of Diseases and Related Health Problems (ICD-10-CM [8]) and [9]. Reed [9] reported that although U.S. physicians are required to use ICD codes on such things as Medicare and Health Insurance claims, since the creation of DSM-IV-TR, there are significant differences between the two manuals regarding "the disorders included, disorder names and definitions, and the organization of categories" (p.458, [9]). Unpacking the confusion around diagnosing paraphilia first requires one to know which diagnostic manual to use. 
One continuing critique of both manuals is that with each new revision come more categories and subtypes, with DSM currently on version 5 and ICD version 10 (version 11 now postponed to 2015). Even though ICD-9 was released in 1979, with ICD-10 approved in 1990, the implementation of ICD-10-CM in the U.S. is due to occur in 2013, over 20 years later. A clinical diagnosis of a paraphilia can therefore be made using either ICD-10 classification codes, from F65.0 - F65.8 ([8], or from DSM-5 [7]). However, ICD-10 does not specifically give a definition for paraphilia; therefore, a common definition used worldwide comes from the DSM-IV (which was not redefined in DSM-5):

"recurrent, intense sexually arousing fantasies, sexual urges, or behaviors generally involving i) non-human objects, ii) the suffering or humiliation of oneself or one's partner, or iii) children or other non-consenting persons that occur over a period of at least 6 months" (p.566, [6]).

Due to societal shift on what is defined as sexually deviant the use of 'paraphilic' has significantly changed over time, and within cultures, and thus strict definitions of a paraphilia are problematic [10,11], and the chair of DSM-V paraphilias subwork group proposed a new definition of paraphilia as:

"any powerful and persistent sexual interest other than sexual interest in copulatory or pre-copulatory behaviour with phenotypically normal, consenting adult human partners" (p.367; [12]).

Moser [13] in his criticism offers that such a definition would define the preference in the sexual masochist for being whipped rather than engage in coitus as paraphilic, yet if the same act is preferred as foreplay to coitus it would be considered normophilic. He also questions whether surgically augmented breasts are considered phenotypically normal, and proposes that if non-consensual acts imply paraphilic behaviour then there is confusion between a criminal act and a mental disorder. Singy [14] suggests this definition and other proposals of DSM-V point to a "cracking of the moral whip" and making psychiatrists into "the guardians of cultural values". However, as previously mentioned, there appears to be no definition change within the DSM-5.

Despite DSM being derived by and written for psychiatric clinicians, it is also used by forensic practitioners as a legal basis for sentencing and/or committing sexually motivated criminals to psychiatric care. A recent article by Frances and First [15] stated that the paraphilia section of DSM-IV-TR was widely misinterpreted, specifically for forensic evaluations of sexually violent predators, leading to "inappropriate medicalization of criminal behaviour to serve a practical public safety purpose" (p.560, [15]) and it had "been twisted in translation within the legal system" (p.78, [16]). Despite changes in DSM-5 in distinguishing 'ascertainment' of a paraphilia from a 'paraphilic disorder', Fedoroff [17], in discussing this then proposed change, suggested that once a person's paraphilic interest was ascertained it would be difficult to imagine that they would not be considered as diagnosed.

The lack of a grounded basis as to what paraphilia is has had dramatic implications on DSM-5 and may impact on the future release of ICD-11. Paraphilia as a concept is "vulnerable to societal pressures rather than advances in science" (p.249, [5]), and so diagnosis may be grounded more in societal norms than in psychiatric health. Keenan [18] in her criticism suggests the inclusion of 'paraphilic disorders' in DSM-5 as redundant, unscientific and stigmatizing, and may cause personal distress by categorizing engagement in, or urges for, atypical sexual behavior as a psychiatric disorder. Some might think that this has parallels in the way certain states today still persecute gay and lesbian individuals who can legitimately seek asylum in 'neoliberal' states such as the U.S. [19]. This raises concerns as to whether such a category should be included at all for psychiatric diagnosis [2], and further needs to be considered with criminal and legal proceedings in mind.

\section{Diagnosis}

"A behavior can be illegal, immoral, and undesirable or cause distress, yet not be an expression of an underlying mental disorder. Something more is required to decide which, if any, of the paraphilias are best conceptualized as psychopathologies" (p.218, [20]).

There is a difficulty in conceptualizing differences between deviant sexual desires arising from mental disorders and displays of sexual orientation that do not emerge from a form of mental illness. Silverstein [2] has predicted that paraphilias are a cultural and timely phenomenon that 'will likely disappear from the DSM for those who have consensual adult-adult sex' (p.162). Although paraphilias have not disappeared from the DSM with their inclusion in the latest addition, DSM-5, there is an attempt to clearly distinguish between the behaviour itself (i.e. sexual masochism) and a disorder stemming from that behaviour (i.e. sexual masochism disorder). To differentiate between atypical sexual interest and a mental disorder, DSM-5 requires that, for diagnosis, people with such interests exhibit the following:

(i) "feel personal distress about their interest, not merely distress resulting from society's disapproval"; or 
(ii) "have a sexual desire or behavior that involves another person's psychological distress, injury, or death, or a desire for sexual behaviors involving unwilling persons or persons unable to give legal consent" [7].

Despite terminological redefining, based on prior criticisms, it would appear that these changes will do little to fan the flames of discontent of those advocating the removal of paraphilias from the DSM. Fedoroff [17] concludes that despite DSM-5 website claims of substantial changes in distinguishing sexual interest from a mental disorder, this is merely a shift in terminology, whilst Moser [21] suggests that any distinction between the two could be meaningless in practice. Whilst preempting this as an advance in distinguishing the two, Fedoroff [17] contests that this would still yield conceptually invalid criteria for paraphilic disorders open to serious forensic abuse.

In the United States, the introduction of 'sexual predator' laws have created a situation of civil commitment for an indefinite period for those who may have completed their prison sentence, but have been diagnosed with a paraphilic mental disorder [22]. This means that following completion of a prison sentence for sexually motivated crime, ex-prisoners can be incarcerated by proxy in nonpunitive institutions. Although such commitment is not technically further punishment, this can bring about concerns for civil liberties and procedural justice. Frances and First [15] argued that the diagnosis of paraphilia has been misapplied to cover a legal loophole following the introduction of fixed sentencing, where many convicted rapists were inadvertently given shorter prison sentences. By inappropriately classing rape as a paraphilia, due to contentions over DSM-IV category of paraphilia 'not otherwise specified', convicted rapists can be committed following their prison term to ensure longer sentencing. Consequently, the diagnosis of paraphilia becomes open to abuse as the line between criminal culpability and psychiatric diagnosis begins to degrade. Whilst diagnostic terminology has changed in DSM-5 to 'other specified and unspecified paraphilic disorder', in line with Fedoroff's [17] argument, it would be difficult not to see ascertainment of an offender's paraphilic interest being diagnosed as a disorder. Fitch [23] surveyed U.S. states that used sexually violent predatory laws and concluded that $85 \%$ of offenders committed under these laws were diagnosed with a paraphilia. A presentation by Perillo and Jeglic [24] reported that within 21 U.S. jurisdictions, 4,500 sex offenders were detained under the civil commitment (sexually violent predator) statute. Thus, the major issue within this area is how to balance societal norms and public perception with the human rights of an individual who could be negatively impacted by diagnosis of paraphilia [25].

\section{Types of paraphilias}

Both the ICD-10 and DSM-IV include eight specific paraphilias outlined with additional 'not otherwise specified (DSM-IV), unspecified (ICD-10), other specified paraphilic disorder and unspecified paraphilic disorder (DSM-5)' categories. Table 1 outlines paraphilias included in the DSM-IV and subsequent changes in DSM-5.

A diagnosis of all non-criminal paraphilias requires that they are present for at least six months and cause clinically important distress, or impair work, or cause problems with social or personal functioning [6]. In advocating the removal of paraphilias from the DSM, Moser and Kleinplatz [26] argue that functioning may be impaired as a result of significant others discovering such sexual interest, therefore it is inappropriate to conclude that the 'paraphilia' per se is the cause of the dysfunction. Keenan [18] offers support for this conclusion, suggesting that the citing of psychiatric understanding of

Table I Diagnostic changes from DSM-IV to DSM-5 and summary definitions of paraphilias

\begin{tabular}{|c|c|c|}
\hline $\begin{array}{l}\text { Paraphilia } \\
\text { DSM-IV diagnosis }\end{array}$ & $\begin{array}{l}\text { Paraphilic Disorder } \\
\text { DSM-5 diagnosis }\end{array}$ & Summary Definitons \\
\hline Exhibitionism & Exhibitionistic Disorder & $\begin{array}{l}\text { Exposing one's genitals to an unsuspecting person or performing sexual acts that } \\
\text { can be watched by others }\end{array}$ \\
\hline Frotteurism & Frotteuristic Disorder & Touching or rubbing against a non-consenting person \\
\hline Voyeurism & Voyeuristic Disorder & $\begin{array}{l}\text { Urges to observe an unsuspecting person who is naked, undressing or engaging in } \\
\text { sexual activities, or in activities deemed to be of a private nature }\end{array}$ \\
\hline Fetishism & Fetishistic Disorder & Use of inanimate objects to gain sexual excitement \\
\hline Paedophilia & Pedophilic Disorder & Sexual preference for prepubescent children \\
\hline Sexual masochism & Sexual Masochism Disorder & $\begin{array}{l}\text { Wanting to be humiliated, beaten, bound or otherwise made to suffer for sexual } \\
\text { pleasure }\end{array}$ \\
\hline Sexual sadism & Sexual Sadism Disorder & In which pain or humiliation of a person is sexually pleasing \\
\hline Transvestic fetishism & Transvestic Fetishism & Arousal from clothing associated with members of the opposite sex \\
\hline Not otherwise specified & $\begin{array}{l}\text { Other Specified Paraphilic } \\
\text { Disorder }\end{array}$ & $\begin{array}{l}\text { These include a variety of paraphilic behaviours such as: partialism; zoophilia; } \\
\text { necrophilia; klismaphilia; coprophilia; urophilia; infantilism; telephone scatologia. }\end{array}$ \\
\hline
\end{tabular}


paraphilias is a partial source of distress in those reporting 'incredible loneliness and pain'. Some other problems with validity and reliability for diagnosis of paraphilia that were proposed for inclusion in DSM-5 are considered for some of the disorders defined. When considering paraphilic coercive disorder, Knight [27] suggested that little empirical justification existed for its proposal as a distinct syndrome in DSM-5. The proposed disorder is mainly based on higher plethysmographic responses to coercive rape scenarios, which Knight suggests may be better explained by failure of these scenarios to inhibit sexual arousal than be the cause of such. In addition, Zonana [5] contended that the proposed combining of pedophilia and hebephilia into 'pedohebephilia' was becoming overly concerned with legal goals rather than defining disorders. For example, a male attracted to a 14-year-old female with mid to advanced adolescent development is not akin clinically to one attracted to a prepubescent 10-year-old. However, much to the dissent of Blanchard [11] and Zucker [4], the ideas for classifying paraphilic coercive disorder as a distinct syndrome and the combining of pedophilia and hebephilia were both rejected for inclusion in DSM-5, with the latter's diagnostic criteria remaining the same as in the DSM-IV-TR.

Despite some proposal rejections, other criticized syndromes remain, such as sexual sadism. Marshall, Kennedy and Yates [26] and Marshall and Kennedy [29] raised concerns regarding reliability of a diagnosis of 'sexual sadism'. These included low levels of agreement between raters, leading them to conclude that DSM-IV-TR criteria for sexual sadism were too vague to allow reliable diagnoses. Zander [30] highlights a lack of research supporting validity and inter-rater reliability of 'paraphilia not otherwise specified', yet it is still widely used for potentially lifetime commitment, as a substitute for a rejected diagnostic category for rapists - the DSM-5 maintains this rejection for such a category. A notable additional change to paraphilic disorders is the opening of the diagnosis of 'transvestic disorder' to include women and gay men who have this sexual interest [7]; however, this diagnosis is once again criticized, as the source of distress for a transvestite is not the behaviour of crossdressing but not being able to cross-dress [17].

\section{Prevalence}

Prevalence rates for paraphilias are difficult to obtain due to changes in criterion over time and between cultures [10]. Ahlers et al. [31] surveyed a sample of 1,915 German men aged $40-79$ and found $62.4 \%$ reported at least one paraphilia-associated sexual arousal pattern, and that this caused distress in only $1.7 \%$ of cases. According to this study, it would appear that prevalence of paraphilic arousal was within the majority and further not considered as distressing. Alternatively, Langstrom and Seto [32] surveyed a sample of 2,450 individuals aged 18-60 years and found that $3.1 \%$ of participants reported at least one incident of being sexually aroused by exposing their genitals to a stranger and $8 \%$ admitted being sexually aroused spying on others having sex. Such large variance in paraphilia prevalence rates in general sampling raises validity concerns over inconsistency. This is possibly due to the intimate and private nature of questionnaires, which may impair validity [25]. In terms of more standardized studies, most data are based on criminal reports or studies using clinical populations referred for legal reasons, rather than for self-help in the general population. For instance, Briken et al. [33] reported that in a study of sexual murderers, there were higher levels of sexual sadism alongside other paraphilic-related interests and disorders. However, prevalence rates are still difficult to report with any certainty, and this is further underpinned by the contentious nature of paraphilia definitions.

\section{Treatment}

There is an abundance of small studies and case reports regarding a variety of pharmacological and psychological treatments within sex offender populations, as captured by Thibaut et al. [25], such as pedophilia, exhibitionism and rape. Whilst research into treatment of other 'noncriminal' paraphilias is negligible, it is reliant on voluntary disclosure, which is very rare, and justification for treatment of such is still very much debatable. Although Thibaut et al. [25] report a moderate decrease in sex offending recidivism with cognitive behavioral therapy (CBT), Beech and Harkins [34] suggest that behavioral therapy such as aversion and reconditioning show little evidence of effectiveness.

Thibaut et al's [25] evaluation of 40 years (1969-2009) of treatment research found that despite some case reports of a reduction of some sexual behaviors, psychotropic drugs showed very poor evidence of effective treatment for paraphilic behaviors. The same was found for antiandrogens, also associated with many side effects including hot flushes, leg cramps, hair loss, bone mineral loss and cardio issues, with the benefit/risk ratio not favoring use of such drugs [25]. Only gonadotropinreleasing hormone treatment showed high efficacy, working in a similar way to physical castration. It rapidly desensitises gonadotropin-releasing hormone receptors, resulting in reduction of luteinizing hormone, which is responsible for the stimulation for release of testosterone in the testes. However, research into all treatments of paraphilia is blighted by small sample sizes, short duration of follow-up, open and retrospective studies, lack of controls and biases, and 
its associated co-morbidity with other disorders. Thus, the effectiveness of treatments for these paraphilias presented is inconclusive.

Moser [21] highlights potential issues with the creation of the ascertainment category in DSM-5 in leading to confusion in treatment goals. Moser goes on to question categorization in the resolving of distress or impairment that is symptomatic with the diagnosed disorder. Would the individual revert back to paraphilic ascertainment, would it be paraphilic disorder in remission or a continuation of paraphilic disorder diagnosis? As well as the impact on treatment goals, it is clear to see the implications such confusion may have on decisionmaking in forensic settings in particular.

\section{Conclusion}

Delineating what is normal versus deviant or disordered sexuality is one of the biggest challenges when using the term paraphilia. The definitions under paraphilia within the DSM have been highly debated and highly controversial [22], and, given the lack of change to definitions and diagnostic criteria in the real sense, this would seem set to continue. The malleability of sexual pleasure across time and cultures creates problems for those defining and diagnosing paraphilia and the efficacy of treatment of paraphilias synonymous with sexual offending is inconclusive. The ability to imprison and/or commit an individual based on their future "dangerousness" using a mental disorder or psychiatric criterion as justification [35,36] may potentially violate due process rights [37]. At the heart of the issues still lies the much debated question: "what justifies the classification of a source of sexual pleasure or a type of sexual activity as a mental disorder" ([22] p.195)?

\section{Abbreviations}

APA, American Psychiatry Association; DSM, diagnostic and statistical manual of mental disorders; ICD, International Classification of Diseases.

\section{Disclosures}

The authors declare that they have no disclosures.

\section{References}

I. Stuart RS: Constructing Perversions: The DSM and the classification of sexual paraphilias and disorders. Electronic J Hum Sex 2012, 15.

\section{FlOOOPrime}

\section{RECOMMENDED}

2. Silverstein $\mathrm{C}$ : The implications of removing homosexuality from the DSM as a mental disorder. Arch Sex Behav 2009, 38:161-3.
3. Cantor JM: Is homosexuality a paraphilia? The evidence for and against. Arch Sex Behav 20I2, 41:237-47.

FlOOOPrime

4. Zucker KJ: DSM-5: Call for Commentaries on Gender Dysphoria, Sexual Dysfunctions, and Paraphilic Disorders. Arch Sex Behav 2013.

5. Zonana $\mathrm{H}$ : Sexual disorders: new and expanded proposals for the DSM-5-do we need them? J Am Acad Psychiatry Law 2011, $39: 245-9$.

\section{FlOOOPrime}

\section{RECOMMENDED}

6. American Psychiatric Association (APA): Diagnostic and statistical manual of mental disorders DSM-IV-TR®. Washington DC: APA; 2000.

7. American Psychiatric Association (APA): Diagnostic and statistical manual of mental disorders DSM-5. Washington DC: APA; 2013.

8. World Health Organization (WHO) ICD- 10 Version:20 I0, Disorders of sexual preference. [http://apps.who.int/classifications/ icd I0/browse/2010/en\#/F65]

9. Reed GM: Toward ICD-I I: Improving the clinical utility of WHO's International Classification of mental disorders. Prof Psychol Res Pr 2010, 41:457-64.

10. Bhugra D, Popelyuk D, McMullen I: Paraphilias across cultures: contexts and controversies. J Sex Res 2010, 47:242-56.

II. Blanchard R: A Dissenting Opinion on DSM-5 Pedophilic Disorder. Arch Sex Behav 2013, 42:675-8.

12. Blanchard R: The DSM diagnostic criteria for transvestic fetishism. Arch Sex Behav 2010, 39:363-72.

13. Moser C: Yet another paraphilia definition fails. Arch Sex Behav 20II, 40:483-5.

14. Singy P: What's wrong with sex? Arch Sex Behav 2010, 39:|23।-3.

15. Frances A, First MB: Paraphilia NOS, nonconsent: not ready for the courtroom. J Am Acad Psychiatry Law 201 I, 39:555-6I.

\section{FlOOOPrime}

\section{RECOMMENDED}

16. Frances A, First MB: Hebephilia is not a mental disorder in DSM-IV-TR and should not become one in DSM-5. J Am Acad Psychiatry Law 20II, 39:78-85.

17. Fedoroff JP: Forensic and diagnostic concerns arising from the proposed DSM-5 criteria for sexual paraphilic disorder. J Am Acad Psychiatry Law 20II, 39:238-4I.

18. Keenan J: We're Kinky, Not Crazy: Including "paraphilic disorders" in the DSM $\mathbf{V}$ is redundant, unscientific, and stigmatizing. The Slate 2013, Mar.

19. Kimmel M, Llewellyn C: Homosexuality, gender nonconformity, and the neoliberal state. J Homosex 2012, 59:1087-94.

20. Quinsey VL: Pragmatic and Darwinian views of the paraphilias. Arch Sex Behav 2012, 41:217-20.

21. Moser C: Problems with ascertainment. Arch Sex Behav 2010, 39:1225-7.

22. Wakefield JC: DSM-5 proposed diagnostic criteria for sexual paraphilias: tensions between diagnostic validity and forensic utility. Int J Law Psychiatry 20I I, 34:195-209.

\section{FlOOOPrime
RECOMMENDED}

23. Fitch WL: Sexual offender commitment in the United States: legislative and policy concerns. Ann N Y Acad Sci 2003, 989:489-50 I.

\section{FlOOOPrime} RECOMMENDED

24. Perillo $A D$, Jeglic EL: The cost of sex offender civil commitment: How much is too much? Presented at The Annual Association for the Treatment of Sexual Abusers (ATSA) conference: October 20I2; Denver, CO 
25. Thibaut F, La Barra F de, Gordon H, Cosyns P, Bradford JMW: The World Federation of Societies of Biological Psychiatry (WFSBP) guidelines for the biological treatment of paraphilias. World J Biol Psychiatry 2010, II:604-55.

\section{FlOOOPrime \\ RECOMMENDED}

26. Moser C, Kleinplatz PJ: DSM-IV-TR and the paraphilias: An argument for removal. J Psychol Human Sex 2005, 17:91-109.

\section{FlOOOPrime}

\section{RECOMMENDED}

27. Knight RA: Is a diagnostic category for paraphilic coercive disorder defensible? Arch Sex Behav 2010, 39:419-26.

\section{FlOOOPrime}

RECOMMENDED

28. Marshall WL, Kennedy P, Yates P: Issues concerning the reliability and validity of the diagnosis of sexual sadism applied in prison settings. Sex Abuse 2002, I4:30I-II.

29. Marshall WL, Kennedy P: Sexual sadism in sexual offenders: An elusive diagnosis. Aggress Violent Behav 2003, 8: I-22.

30. Zander TK: Commentary: inventing diagnosis for civil commitment of rapists. J Am Acad Psychiatry Law 2008, 36:459-69.

31. Ahlers CJ, Schaefer GA, Mundt IA, Roll S, Englert H, Willich SN, Beier KM: How unusual are the contents of paraphilias?
Paraphilia-associated sexual arousal patterns in a communitybased sample of men. J Sex Med 20I I, 8:I362-70.

FIOOOPRime

32. Långström N, Seto MC: Exhibitionistic and voyeuristic behavior in a Swedish national population survey. Arch Sex Behav 2006, 35:427-35.

\section{FlOOOPrime}

RECOMMENDED

33. Briken P, Habermann N, Kafka MP, Berner W, Hill A: The paraphilia-related disorders: an investigation of the relevance of the concept in sexual murderers. J Forensic Sci 2006, 5 I :683-8.

\section{FlOOOPrime}

RECOMMENDED

34. Beech AR, Harkins L: DSM-IV paraphilia: Descriptions, demographics and treatment interventions. Aggress Violent Behav 2012, 17:527-39.

35. Kansas v. Crane - 534 U.S. 407 (2002).

36. Kansas v. Hendricks - 52I U.S. 346 (1997).

37. Hinderliter AC: Defining paraphilia in DSM-5: do not disregard grammar. J Sex Marital Ther 20II, 37:17-3I. 